\title{
Case Study in a Conceptual DFT Investigation of New Corrosion Inhibitor
}

\author{
Ahmed A. Alamiery ${ }^{1, *}$ (D) \\ 1 Department of Chemical and Process Engineering, Faculty of Engineering and Built Environment, University Kebangsaan \\ Malaysia (UKM), P.O. Box: 43000, Bangi, Selangor, Malaysia \\ * Correspondence: dr.ahmed1975@ukm.edu.my (A.A.A.);
}

Scopus Author ID 42060956400

Received: 24.08.2021; Revised: 10.10.2021; Accepted: 14.10.2021; Published: 30.10.2021

\begin{abstract}
Inhibition efficiency of thiosemicarbazide derivative, namely 4-ethyl-1-(4-oxo-4phenylbutanoyl)thiosemicarbazide (EOPT) on corrosion of mild steel, was investigated utilizing the density functional theory (DFT) modeling techniques in the aqueous phase. Chemical parameters at the quantum level, such as energies of highest occupied molecular orbital (HOMO), lowest unoccupied molecular orbital (LUMO), dipole moment $(\mu)$, absolute electronegativity $(\chi)$, global hardness $(\eta)$, softness $(\sigma)$, and the fraction of electrons transferred $(\Delta \mathrm{N})$ have been determined at the B3LYP level of theory with $6-31 \mathrm{G}(\mathrm{d}, \mathrm{p})$ basis set.
\end{abstract}

Keywords: corrosion inhibition; DFT; simulation; mild steel; thiosemicarbazide derivative.

(C) 2021 by the authors. This article is an open-access article distributed under the terms and conditions of the Creative Commons Attribution (CC BY) license (https://creativecommons.org/licenses/by/4.0/).

\section{Introduction}

Mild steel is a popular choice due to its inexpensive cost and ease of supply. Acids are used in various applications, including pickling, boiler cleaning, descaling, and oil well acidification. Corrosion inhibitors are commonly used to reduce the undesirable dissolution of base metals resulting from these processes [1-14]. The association between the structure of the inhibitor and its sorption properties has been the subject of studies on organic corrosion inhibitors. It has been discovered that the adsorption of inhibitor molecules is significantly influenced by physical and chemical features such as functional groups, esterifying agents, odors, the electron density in donor atoms, and the pi orbital nature of donor electrons [15-23]. It also depends on the electrical structure of the molecules. As a result, the efficiency of an organic compound is largely determined by its ability to adsorb on the metal surface [24-31]. Displacement of water molecules adsorbed by inhibitor species leads to selective adsorption of the inhibitor on the metal surface, which leads to corrosion inhibition (Equation 1).

$$
\operatorname{Org}_{(\text {sol })}+\mathrm{xH}_{2} \mathrm{O} \rightarrow \operatorname{Org}_{(\text {ads })}+\mathrm{xH}_{2} \mathrm{O}_{(\text {sol })}
$$

Moreover, experimental procedures are expensive and time-consuming; as a result, the process of lighting wear usually suffers. Computer simulation has become a useful tool for investigating complex corrosion resistance systems due to advances in software and technology. The corrosion mechanism is now fully understood by examining the structure, electron distribution, and molecular adsorption on metal and oxide surfaces [32]. In 1971, Vosta and Eliasek [33-35] established the topic of quantum corrosion electrochemistry by introducing quantum chemical approaches to research corrosion blocking. Subsequently, the primary goal of quantitative chemical approaches was to identify and establish relationships 
between molecular structure and activity, and many useful results have since been published. Quantitative chemical analysis has long been shown to be useful in determining the structure of molecules, interactions, and apparent electronic structures [36-38]. As a result, the computation of the chemical corrosion investigation to evaluate the efficiency of corrosion inhibitors with the help of mathematical modeling using chemical compounds to find compounds with preferred properties based on experience in mathematical quantum and the relationship between molecular structure once it is computed and worked. Found, any number of compounds became normal practice. Those not yet synthesized can be easily tested using a computational approach [39-48] and a set of mathematical equations that accurately display the chemical incident under investigation. The inhibitive characteristics of the 4-ethyl-1-(4oxo-4-phenylbutanoyl)thiosemicarbazide (Figure 1) have been studied on the mild steel utilizing energies of highest occupied molecular orbital (HOMO), lowest unoccupied molecular orbital (LUMO), dipole moment $(\mu)$, absolute electronegativity $(\chi)$, global hardness $(\eta)$, softness $(\sigma)$, and the fraction of electrons transferred $(\Delta N)$ as quantum chemical parameters. The current investigation found that the DFT method can be efficiently utilized to screen organic corrosion inhibitor molecules preparatory to experimental analysis.<smiles>CCNC(=S)NNC(=O)CCC(=O)c1ccccc1</smiles>

Figure 1. The chemical structure of the studied inhibitor.

\section{Materials and Methods}

\subsection{Computational details.}

The optimized molecular structure of PMO molecule was geometrically by DFT method with the 6-31G $(\mathrm{d}, \mathrm{p})$ basis set. Gaussian 09 software was used. The quantum electronic parameters of the most stable conformers were calculated of the DFT. HOMO, LUMO, $\Delta \mathrm{E}, \eta$, $\sigma, \chi$, and $\Delta \mathrm{N}$ were calculated using equations $(2-6)[49,50]$.

$$
\begin{aligned}
& \Delta E=E_{\text {HOMO }}-E_{\text {LUMO }} \\
& \eta=-\frac{E_{\text {HOMO }}-E_{\text {LUMO }}}{2} \\
& \sigma=\frac{1}{\eta} \\
& \chi=-\frac{E_{\text {HOMO }}+E_{\text {LUMO }}}{2} \\
& \Delta N=\frac{\chi_{\mathrm{Fe}}-\chi_{\text {inh }}}{2\left(\eta_{\mathrm{Fe}}+\eta_{\text {inh }}\right)}
\end{aligned}
$$

where $\chi \mathrm{Fe}$ and $\eta \mathrm{Fe}$ were $7 \mathrm{eV} / \mathrm{mol}$ and $0 \mathrm{eV} / \mathrm{mol}$, respectively.

\section{Results and Discussion}

\subsection{Quantum chemical calculations.}

The global molecular interaction was investigated using the study of frontier molecular orbitals (FMO) in terms of the interaction between the frontier orbitals, including HOMO and LUMO. The ability of a molecule to donate electrons is referred to as EHOMO. As a result, 
large EHOMO values aid electron transport to an acceptor that has an empty orbital. LUMO energy, on the other hand, relates to a molecule's ability to receive electrons. The inhibitory efficacy improves when EHOMO values climb. High EHOMO values imply that a low-energy empty molecular orbital molecule tends to give electrons to the right acceptor molecules. Absolute stiffness is a key parameter in molecular interaction and stability research. The softest base inhibitors are the most effective in eroding the softest materials, according to published studies; according to Wu et al. [51], .'s damper sections with higher smoothness and lower hardness are helpful. The tendency of an atom in a molecule to attract electrons is described by its electronegativity. As a result, electrons from a lower electronegative molecule will be partially transferred to a greater electronegative molecule (electrons flow from a high chemical potential to a lower chemical potential). Excellent inhibitors contribute electrons to the metal substrate, and thus the electronegativity values are expected to decrease as the inhibitory efficacy improves. In addition, Table 1 summarizes the $\chi$ value of the current system. The trend in the $\chi$ value of the respective inhibitor indicates that the tested inhibitor has a low electronegativity. Its adsorption on the surface of mild steel increases due to this process, and its anti-corrosion efficiency improves. Each species' quantity of electrons transported $(\Delta \mathrm{N})$ is likewise identified and reported in Table 1. Molecules that have a positive number of transferred electrons $(\Delta \mathrm{N})$ are electron donors, while those with a negative number of transferred electrons $(\Delta \mathrm{N})$ are electron acceptors [52]. As a result, in the current system, all species operate as electron donors. Corrosion inhibitors with a higher $\mathrm{N}$ content have a stronger desire to interact with the metal surface. The tested inhibitor has the highest $\Delta \mathrm{N}$ value according to the $\Delta \mathrm{N}$ value for species. As a result, the best inhibitor is closely associated with the biggest percent of electrons transferred, whereas the lowest fraction is linked to the inhibitor with the lowest inhibitory efficacy [53]. Density function theory (DFT) as a quantitative chemical calculation method can be used to investigate the adsorption capacity of EOPT composite on mild steel surfaces [54]. The adsorption of the investigated inhibitor may be demonstrated by the interactions between the donor and the acceptor (EOPT). On the surface of mild steel, electrons are moved from the highly electronegative centers of organic molecules (oxygen, sulfur, nitrogen, and pi-electrons) to the vacant $3 \mathrm{~d}$-orbital of iron atoms. The quantum chemical properties produced from the EOPT optimization molecular structure, as shown in Figure 2 and summarized in Table 1, will be discussed in more detail below. The highest occupied molecular orbital energy represents the investigated compound's electron donating activity (EHOMO).

A lower ELUMO value indicates the inhibitor molecules' capacity to absorb electrons from donating the iron backing, hence enhancing the binding energy between the mild steel surface and the inhibitor molecules.

The more successful the adsorption/bonding of the investigated inhibitor with the metallic surface, the higher the HOMO energy value and the lower the LUMO energy value [55].

A lower ELUMO value indicates the inhibitor molecules' capacity to absorb electrons from donating the iron backing, hence enhancing the binding energy between the mild steel surface and the inhibitor molecules.

The more successful the adsorption/bonding of the investigated inhibitor with the metallic surface, the higher the HOMO energy value and the lower the LUMO energy value [55]. The EOPT molecules aggregate on the mild steel surface when the dipole moment decreases, increasing the adsorption capacity of the EOPT molecules [57]. The global hardness 
$(\eta)$, softness $(\sigma)$, electronegativity $(\chi)$, and the fraction of electron transfer $(\Delta N)$ collectively describe the dynamic parameters that are calculated as presented in Table 1 . The soft molecule has a smaller energy gap and higher basicity than the hard one, according to the hard-soft acidbase principle [58]. As a result of its easier electron transfer and better corrosion inhibitor than the hard molecule, the soft molecule possesses adsorption capability. According to Lukovit's research, the inhibitory effectiveness as a function of electron transfer improves when the number of electrons communicated $(\Delta \mathrm{N})$ is smaller than 3.6 [59]. The higher the electron transfer fraction $(\Delta \mathrm{N})$, the better the corrosion inhibitor. As indicated in Table 1, N increases as the number of inhibitor molecules increases, indicating that the electrosorption efficiency is greater. Ionization energy [60] represents the chemical reaction of atoms and molecules.
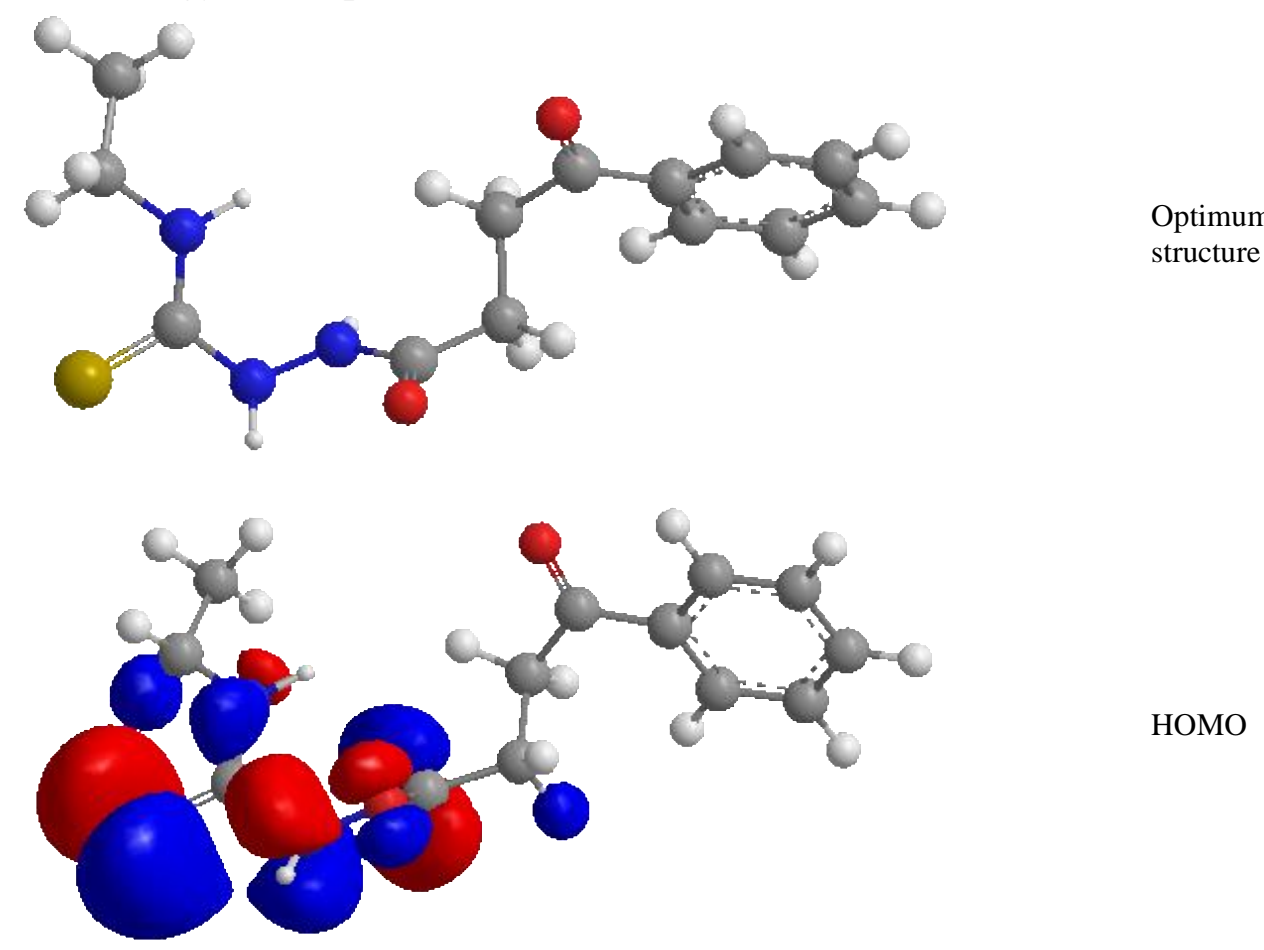

HOMO

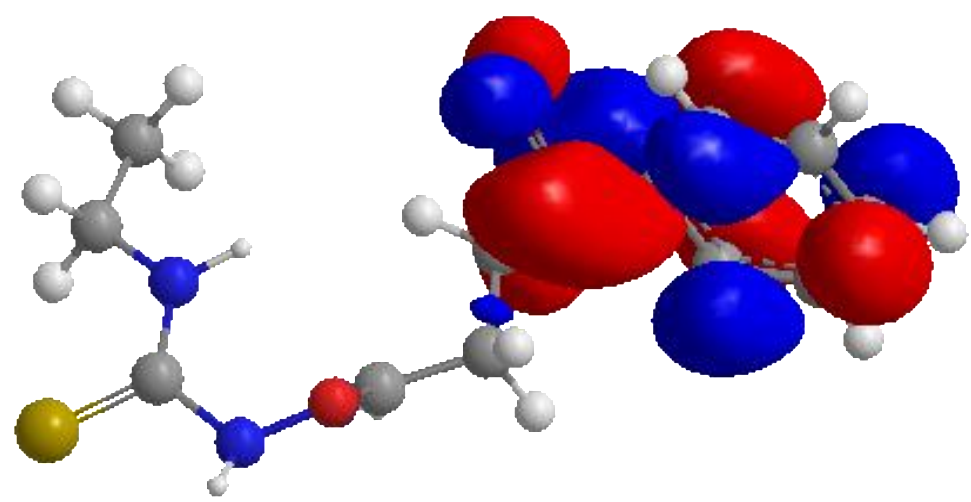

LUMO

Figure 2. Optimized structure, highest occupied molecular orbital (HOMO), and lowest unoccupied molecular orbital (LUMO).

Table 1. Chemical parameters of the studied Inhibitor.

\begin{tabular}{l|c|c|c|c|c|c|c|c|c} 
Inhibitor & Eномо & $\mathbf{E}_{\text {LUMo }}$ & $\boldsymbol{\Delta} \mathbf{E}(\mathbf{e V})$ & $\mathbf{A}$ & $\mathbf{I}$ & $\boldsymbol{\chi}(\mathbf{e V})$ & $\boldsymbol{\eta}(\mathbf{e V})$ & $\boldsymbol{\Delta} \mathbf{N}(\mathbf{e V})$ & $\boldsymbol{\mu}(\mathbf{D})$ \\
\hline EOPT & -8.785 & -4.940 & 3.845 & 4.940 & 8.785 & 6.862 & 1.922 & 1.517 & 4.265
\end{tabular}

\subsection{Mulliken charges.}

When it comes to determining inhibitor adsorption sites, the Mulliken charge measurement is crucial. As the negatively charged heteroatom becomes increasingly negatively 
charged, the ability to be adsorbed on the metallic surface rises. In EOPT, higher negative charges surround nitrogen, sulfur, oxygen, and some carbon atoms, indicating that these are the inhibitors' coordinating sites. The nitrogen connected as $\mathrm{N}$-amide and $\mathrm{N}$-thioamide, on the other hand, shows that the binding sites with higher negative Mulliken charges were chosen. Mulliken charges are summarised in Table 2.

Table 2. The Mulliken charges of EOPT molecules.

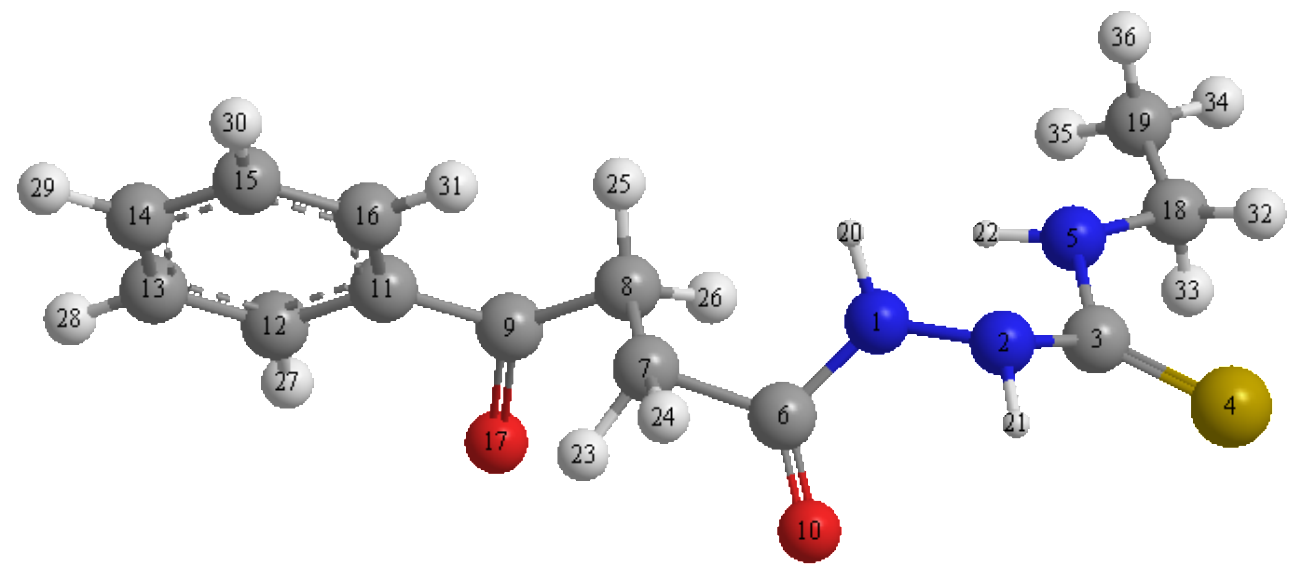

\begin{tabular}{l|l|l|l}
\hline No. & Atom & Atom type & Mulliken Charges \\
\hline $\mathbf{1}$ & $\mathrm{N}(1)$ & N Amide & -0.3415 \\
\hline $\mathbf{2}$ & $\mathrm{N}(2)$ & N Thioamide & -0.1582 \\
\hline $\mathbf{3}$ & $\mathrm{C}(3)$ & C Thiocarbonyl & 0.0873 \\
\hline $\mathbf{4}$ & $\mathrm{S}(4)$ & S Thiocarbonyl & -0.2471 \\
\hline $\mathbf{5}$ & $\mathrm{N}(5)$ & N Thioamide & -0.3011 \\
\hline $\mathbf{6}$ & $\mathrm{C}(6)$ & C Carbonyl & 0.287 \\
\hline $\mathbf{7}$ & $\mathrm{C}(7)$ & C Alkane & -0.1721 \\
\hline $\mathbf{8}$ & $\mathrm{C}(8)$ & C Alkane & -0.2055 \\
\hline $\mathbf{9}$ & $\mathrm{C}(9)$ & C Carbonyl & 0.2658 \\
\hline $\mathbf{1 0}$ & $\mathrm{O}(10)$ & O Carbonyl & -0.324 \\
\hline $\mathbf{1 1}$ & $\mathrm{C}(11)$ & C Alkene & -0.1579 \\
\hline $\mathbf{1 2}$ & $\mathrm{C}(12)$ & C Alkene & -0.0709 \\
\hline $\mathbf{1 3}$ & $\mathrm{C}(13)$ & C Alkene & -0.142 \\
\hline $\mathbf{1 4}$ & $\mathrm{C}(14)$ & C Alkene & -0.096 \\
\hline $\mathbf{1 5}$ & $\mathrm{C}(15)$ & C Alkene & -0.1444 \\
\hline $\mathbf{1 7}$ & $\mathrm{C}(16)$ & C Alkene & -0.0906 \\
\hline $\mathbf{1 8}$ & $\mathrm{O}(17)$ & O Carbonyl & -0.2815 \\
\hline $\mathbf{1 9}$ & $\mathrm{C}(18)$ & C Alkane & -0.0365 \\
\hline & & C Alkane & -0.232
\end{tabular}

\subsection{Suggested mechanism of inhibition.}

The initial step in any corrosion inhibition is the adsorption of the inhibitor on the mild steel surface. According to theoretical findings, EOPT is adsorbed on a mild steel surface through a chemical reaction in which unpaired electrons (on the $\mathrm{N}, \mathrm{S}$, and $\mathrm{O}$ atoms) are transferred from inhibitor molecules (EOPT) to the vacant d-orbital of iron atoms at the mild steel surface, forming coordination bonds, and a very stable complex from inhibitor molecules covers the mild steel surface as a protected layer. The inhibitor is a charged molecule with a strong inductive and extremely strong resonance effect due to the position of the benzene ring and the functional groups thion, carbonyl, and amino. The aromatic ring, which contains thion and carbonyl groups, boosts electron delocalization, making it more reactive. Despite the fact that the carbonyl, thion, and amine (oxygen, sulfur, and nitrogen atoms) each have only one pair of electrons, the inhibitor is preferentially adsorbed onto the metal surface via these functional groups. Figure 3 depicts the proposed chemisorption-based inhibitory mechanism. 


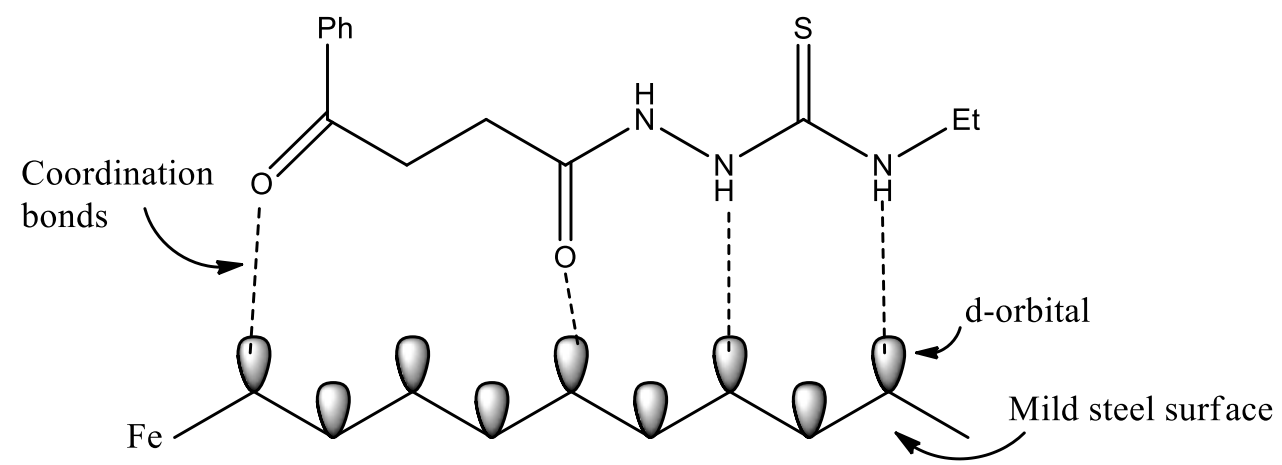

Figure 3. The suggested inhibition mechanism of EOPT molecules.

\section{Conclusions}

The corrosion inhibitor 4-ethyl-1-(4-oxo-4-phenylbutanoyl)thiosemicarbazide (EOPT) was explored using DFT theoretical results. The results of the calculations show that the tested inhibitor is a promising and important corrosion inhibitor. At the B3LYP level of theory using the 6-31G $(\mathrm{d}, \mathrm{p})$ basis set, quantum chemical parameters such as frontier molecular orbitals (HOMO and LUMO), dipole moment, absolute electronegativity, global hardness, softness, and the proportion of electrons transported have been determined. The results back up the validity of the quantum chemical technique adopted in this research. The investigated inhibitor had the strongest tendency to adsorb strongly onto the metal surface, according to quantum chemical calculations..

\section{Funding}

This research received no external funding.

\section{Acknowledgments}

The authors are grateful to the University Kebangsaan Malaysia (UKM) for support.

\section{Conflicts of Interest}

The authors declare no conflict of interest.

\section{References}

1. Al-Baghdadi, S.; Gaaz, T.S.; Al-Adili, A.; Al-Amiery, A.A.; Takriff, M.S. Experimental Studies on Corrosion Inhibition Performance of Acetylthiophene Thiosemicarbazone for Mild Steel in HCl Complemented with DFT Investigation. Int. J. Low-Carbon Technol. 2021, 16, 181-188, https://doi.org/10.1093/ijlct/ctaa050.

2. Zinad, D.S.; Mahal, A.; Al-Amiery, A. An Efficient Synthesis of Novel Imidazo-Aminopyridinyl Derivatives from 2-Chloro-4-Cyanopyridine. Org. Prep. Proced. Int. 2020, 52, 361-367, https://doi.org/10.1080/00304948.2020.1767491.

3. Al-Taweel, S.S.; Gaaz, T.S.; Shaker, L.M.; Al-Amiery, A. Protection of Mild Steel in H2so4 Solution with 3-((3-(2-Hydroxyphenyl)-5-Thioxo-1,2,4-Triazol-4-Yl)Imino)Indolin-2-One. Int. J. Corros. Scale Inhib. 2020, 9, 1014-1024, https://doi.org/10.17675/2305-6894-2020-9-3-14.

4. Al-Amiery, A.; Shaker, L.M.; Kadhum, A.A.H.; Takriff, M.S. Synthesis, Characterization and Gravimetric Studies of Novel Triazole-Based Compound. Int. J. Low-Carbon Technol. 2020, 15, 164-170, https://doi.org/10.1093/ijlct/ctz067.

5. Sheet, E.A.E.; Yamin, J.A.A.; Al-Salihi, H.A.; Salam, A.Q.; Reda, K.S.; Ahmed, W.K.; Mahdi, M.T.; AlAmiery, A.A. N-(3-Nitrobenzylidene)-2-Aminobenzothiazole as New Locally Available Corrosion Inhibitor for Iraqi Oil Industry. J. Balk. Tribol. Assoc. 2020, 26, 194-203.

6. Salman, A.Z.; Jawad, Q.A.; Ridah, K.S.; Shaker, L.M.; Al-Amiery, A.A. Selected BIS-Thiadiazole: Synthesis and Corrosion Inhibition Studies on Mild Steel in HCL Environment. Surf. Rev. Lett. 2020, 27, 1-5, https://doi.org/10.1142/S0218625X20500146. 
7. Salim, R.D.; Jawad, Q.A.; Ridah, K.S.; Shaker, L.M.; Al-Amiery, A.A.; Kadhum, A.A.H.; Takriff, M.S. Corrosion Inhibition of Thiadiazole Derivative for Mild Steel in Hydrochloric Acid Solution. Int. J. Corros. Scale Inhib. 2020, 9, 550-561, https://doi.org/10.17675/2305-6894-2020-9-2-10.

8. Hanoon, M.; Zinad, D.S.; Resen, A.M.; Al-Amiery, A.A. Gravimetrical and Surface Morphology Studies of Corrosion Inhibition Effects of a 4-Aminoantipyrine Derivative on Mild Steel in a Corrosive Solution. Int. J. Corros. Scale Inhib. 2020, 9, 953-966, https://doi.org/10.17675/2305-6894-2020-9-3-10.

9. Kadhim, A.; Sulaiman, G.; Abdel Moneim, A.E.; Yusop, R.M.; Al-Amiery, A. Synthesis and Characterization of Triazol Derivative as New Corrosion Inhibitor for Mild Steel in 1M HCl Solution Complemented with Antibacterial Studies. J. Phys. Conf. Ser. 2021, 1795, https://doi.org/10.1088/1742-6596/1795/1/012011.

10. Al-Baghdadi, S.B.; Kadhim, A.; Sulaiman, G.; Al-Amiery, A.A.; Abdul Amir, H.K.; Takriff, M.S. Anticorrosion and Antibacterial Effects of New Schiff Base Derived from Hydrazine. J. Phys. Conf. Ser. 2021, 1795, https://doi.org/10.1088/1742-6596/1795/1/012021.

11. Alamiery, A.; Shaker, L.M.; Allami, T.; Kadhum, A.H.; Takriff, M.S. A Study of Acidic Corrosion Behavior of Furan-Derived Schiff Base for Mild Steel in Hydrochloric Acid Environment: Experimental, and Surface Investigation. Mater. Today Proc. 2021, 44, 2337-2341, https://doi.org/10.1016/j.matpr.2020.12.431.

12. Shaker, L.M.; Al-Adili, A.; Al-Amiery, A.A.; Takriff, M.S. The Inhibition of Mild Steel Corrosion in $0.5 \mathrm{M}$ H2SO4solution by N-Phenethylhydrazinecarbothioamide (N-PHC). J. Phys. Conf. Ser. 2021, 1795, https://doi.org/10.1088/1742-6596/1795/1/012009.

13. Eltmimi, A.J.M.; Alamiery, A.; Allami, A.J.; Yusop, R.M. Inhibitive Effects of a Novel Efficient Schiff Base on Mild Steel in Hydrochloric Acid Environment. Int. J. Corros. Scale Inhib. 2021, 4, 634-648, https://doi.org/10.17675/2305-6894-2021-10-2-10.

14. Kadhim, A.; Al-Amiery, A. A.; Alazawi, R.; Al-Ghezi, M.K.S.; Abass, R.H. Corrosion Inhibitors. A Review. Int. J. Corros. Scale Inhib. 2021, 10, 54-67, https://doi.org/10.17675/2305-6894-2021-10-1-3.

15. Resen, A.M.; Hanoon, M.M.; Alani, W.K.; Kadhim, A.; Mohammed, A.A.; Gaaz, T.S.; Kadhum, A.A.H.; Al-Amiery, A.A.; Takriff, M.S. Exploration of 8-Piperazine-1-Ylmethylumbelliferone for Application as a Corrosion Inhibitor for Mild Steel in Hydrochloric Acid Solution. Int. J. Corros. Scale Inhib. 2021, 10, 368387. https://doi.org/10.17675/2305-6894-2021-10-1-21.

16. Hanoon, M.M.; Resen, A.M.; Shaker, L.M.; Kadhum, A.A.H.; Al-Amiery, A.A. Corrosion Investigation of Mild Steel in Aqueous Hydrochloric Acid Environment Using N-(Naphthalen-1yl)-1-(4Pyridinyl)Methanimine Complemented with Antibacterial Studies. Biointerface Res. Appl. Chem. 2021, 11, 9735-9743, https://doi.org/10.33263/BRIAC112.97359743.

17. Hashim, F.G.; Salman, T.A.; Al-Baghdadi, S.B.; Gaaz, T.; Al-Amiery, A.A. Inhibition Effect of HydrazineDerived Coumarin on a Mild Steel Surface in Hydrochloric Acid. Tribologia 2020, 37, 3-4, https://doi.org/10.30678/FJT.95510.

18. Gaaz, T.S.; Dakhil, R.M.; Jamil, D.M.; Al-Amiery, A.A.; Kadhum, A.A.; Takriff, M. Evaluation of Green Corrosion Inhibition by Extracts of Citrus Aurantium Leaves against Carbon Steel in $1 \mathrm{~m} \mathrm{Hcl} \mathrm{Medium}$ Complemented with Quantum Chemical Assessment. Int. J. Thin Film Sci. Technol. 2020, 9, 171-179, https://doi.org/10.18576/ijtfst/090307.

19. Braihi, A.J.; Jawad, A.J.; Kadhum, A.A.H.; Aljibori, H.S.S.; Al-Amiery, A.A. Chemical Resistance of N/SB Rubber Blends for Surfaces Corrosion Protection of Metallic Tanks in Petrochemical Industries. Koroze a Ochr. Mater. 2020, 64, 65-71, https://doi.org/10.2478/kom-2020-0010.

20. Al-Amiery, A.A.; Shaker, L.M. Corrosion Inhibition of Mild Steel Using Novel Pyridine Derivative in $1 \mathrm{M}$ Hydrochloric Acid. Koroze a Ochr. Mater. 2020, 64, 59-64, https://doi.org/10.2478/kom-2020-0009.

21. Salman, T.A.; Jawad, Q.A.; Hussain, M.A.M.; Al-Amiery, A.A.; Shaker, L.M.; Kadhum, A.A.H.; Takriff, M.S. New Environmental Friendly Corrosion Inhibitor of Mild Steel in Hydrochloric Acid Solution: Adsorption and Thermal Studies. Cogent Eng. 2020, 7, https://doi.org/10.1080/23311916.2020.1826077.

22. Salman, T.A.; Jawad, Q.A.; Hussain, M.A.M.; Al-Amiery, A.A.; Mohamed, L.; Kadhum, A.A.H.; Takriff, M.S. Novel Ecofriendly Corrosion Inhibition of Mild Steel in Strong Acid Environment: Adsorption Studies and Thermal Effects. Int. J. Corros. Scale Inhib. 2019, 8, 1123-1137, https://doi.org/10.17675/2305-68942019-8-4-19.

23. Salman, T.A.; Al-Amiery, A.A.; Shaker, L.M.; Kadhum, A.A.H.; Takriff, M.S. A Study on the Inhibition of Mild Steel Corrosion in Hydrochloric Acid Environment by 4-Methyl-2-(Pyridin-3-Yl)Thiazole-5Carbohydrazide. Int. J. Corros. Scale Inhib. 2019, 8, 1035-1059, https://doi.org/10.17675/2305-6894-20198-4-14.

24. Jawad, Q.A.; Zinad, D.S.; Salim, R.D.; Al-Amiery, A.A.; Gaaz, T.S.; Takriff, M.S.; Kadhum, A.H. Synthesis, Characterization, and Corrosion Inhibition Potential of Novel Thiosemicarbazone on Mild Steel in Sulfuric Acid Environment. Coatings 2019, 9, https://doi.org/10.3390/coatings9110729.

25. Al-Majedy, Y.K.; Ibraheem, H.H.; Falih, M.S.; Al-Amiery, A.A. New Coumain Derivatives as Corrosion Inhibitor. In IOP Conference Series: Materials Science and Engineering 2019, 579, https://doi.org/10.1088/1757-899X/579/1/012051.

26. Ahmed, M.H.O.; Al-Amiery, A.A.; Al-Majedy, Y.K.; Kadhum, A.A.H.; Mohamad, A.B.; Gaaz, T.S. Synthesis and Characterization of a Novel Organic Corrosion Inhibitor for Mild Steel in 1 M Hydrochloric Acid. Results Phys. 2018, 8, 728-733. 
27. Habeeb, H.J.; Luaibi, H.M.; Dakhil, R.M.; Kadhum, A.A.H.; Al-Amiery, A.A.; Gaaz, T.S. Development of New Corrosion Inhibitor Tested on Mild Steel Supported by Electrochemical Study. Results Phys. 2018, 8, 1260-1267, https://doi.org/10.1016/j.rinp.2018.02.015.

28. Habeeb, H.J.; Luaibi, H.M.; Abdullah, T.A.; Dakhil, R.M.; Kadhum, A.A.H.; Al-Amiery, A.A. Case Study on Thermal Impact of Novel Corrosion Inhibitor on Mild Steel. Case Stud. Therm. Eng. 2018, 12, 64-68, https://doi.org/10.1016/j.csite.2018.03.005.

29. Al-Azawi, K.F.; Mohammed, I.M.; Al-Baghdadi, S.B.; Salman, T.A.; Issa, H.A.; Al-Amiery, A.A.; Gaaz, T.S.; Kadhum, A.A.H. Experimental and Quantum Chemical Simulations on the Corrosion Inhibition of Mild Steel by 3-((5-(3,5-Dinitrophenyl)-1,3,4-Thiadiazol-2-Yl)Imino)Indolin-2-One. Results Phys. 2018, 9, 278283, https://doi.org/10.1016/j.rinp.2018.02.055.

30. Jamil, D.M.; Al-Okbi, A.K.; Al-Baghdadi, S.B.; Al-Amiery, A.A.; Kadhim, A.; Gaaz, T.S.; Kadhum, A.A.H.; Mohamad, A.B. Experimental and Theoretical Studies of Schiff Bases as Corrosion Inhibitors. Chem. Cent. J. 2018, 12, https://doi.org/10.1186/s13065-018-0376-7.

31. Khaled, K.F.; Amin, M.A. Dry and Wet Lab Studies for Some Benzotriazole Derivatives as Possible Corrosion Inhibitor for Copper in $1.0 \mathrm{M}$ HNO3. Corros. Sci. 2009, 51, 2098-2106, https://doi.org/10.1016/j.corsci.2009.05.038.

32. Vosta, J.; Eliasek, J. Study on Corrosion Inhibition from Aspect of Quantum Chemistry. Corros. Sci. 1971, 11, 223-229, https://doi.org/10.1016/S0010-938X(71)80137-3.

33. Al-Azawi, K.F.; Al-Baghdadi, S.B.; Mohamed, A.Z.; Al-Amiery, A.A.; Abed, T.K.; Mohammed, S.A.; Kadhum, A.A.H.; Mohamad, A.B. Synthesis, Inhibition Effects and Quantum Chemical Studies of a Novel Coumarin Derivative on the Corrosion of Mild Steel in a Hydrochloric Acid Solution. Chem. Cent. J. 2016, 10, 1-9, https://doi.org/10.1186/s13065-016-0170-3.

34. Al-Amiery, A.; Kadhum, A.; Alobaidy, A.H.; Mohamad, A.; Hoon, P. Novel Corrosion Inhibitor for Mild Steel in HCl. Materials (Basel). 2014, 7, 662-672, https://doi.org/10.3390/ma7020662.

35. Al-Amiery, A.A.; Binti Kassim, F.A.; Kadhum, A.A.H.; Mohamad, A.B. Synthesis and Characterization of a Novel Eco-Friendly Corrosion Inhibition for Mild Steel in $1 \mathrm{M}$ Hydrochloric Acid. Sci. Rep. 2016, 6, 1-13, https://doi.org/10.1038/srep19890.

36. Abdallah, M.; Asghar, B.; Zaafarany, I.; Fouda, A. The Inhibition of Carbon Steel Corrosion in Hydrochloric Acid Solution Using Some Phenolic Compounds. Int. J. Electrochem. Sci. 2012, 7, 282-304.

37. Khaled, M. Evaluation of Cysteine as Environmentally Friendly Corrosion Inhibitor for Copper in Neutral and Acidic Chloride Solutions. Electrochim. Acta. 2007, 52, 7811-7819, https://doi.org/10.1016/j.electacta.2007.02.053.

38. Junaedi, S.; Kadhum, A.A H.; Al-Amiery, A.A.B.; Mohamad, A.B.; Takriff, M.S. Synthesis and Characterization of Novel Corrosion Inhibitor Derived from Oleic Acid: 2-Amino 5-Oleyl-1,3,4-Thiadiazol (AOT). Int. J. Electrochem. Sci. 2012, 7, 3543-3554.

39. Al-Amiery, A.; Salman, T.A.; Alazawi, K.F.; Shaker, L.M.; Kadhum, A.A.H.; Takriff, M.S. Quantum Chemical Elucidation on Corrosion Inhibition Efficiency of Schiff Base: DFT Investigations Supported by Weight Loss and SEM Techniques. Int. J. Low-Carbon Technol. 2020, 15, 202-209, https://doi.org/10.1093/ijlct/ctz074.

40. Al-Amiery, A.A. Anti-Corrosion Performance of 2-Isonicotinoyl-n-Phenylhydrazinecarbothioamide for Mild Steel Hydrochloric Acid Solution: Insights from Experimental Measurements and Quantum Chemical Calculations. Surf. Rev. Lett. 2021, 28, 1-8, https://doi.org/10.1142/S0218625X20500584.

41. Al-Baghdadi, S.B.; Al-Amiery, A.A.; Kadhum, A.A.; Takriff, M.S. Computational Calculations, Gravimetrical, and Surface Morphological Investigations of Corrosion Inhibition Effect of Triazole Derivative on Mild Steel in HCl. J. Comput. Theor. Nanosci. 2020, 17, 4797-4804, https://doi.org/10.1166/jctn.2020.9328.

42. Yamin, J.A.A.; Ali Eh Sheet, E.; Al-Amiery, A. Statistical Analysis and Optimization of the Corrosion Inhibition Efficiency of a Locally Made Corrosion Inhibitor under Different Operating Variables Using RSM. Int. J. Corros. Scale Inhib. 2020, 9, 502-518, https://doi.org/10.17675/2305-6894-2020-9-2-6.

43. Jawad, Q.A.; Hameed, A.Q.; Abood, M.K.; Al-Amiery, A.A.; Shaker, L.M.; Kadhum, A.A.H.; Takriff, M.S. Synthesis and Comparative Study of Novel Triazole Derived as Corrosion Inhibitor of Mild Steel in Hcl Medium Complemented with Dft Calculations. Int. J. Corros. Scale Inhib. 2020, 9, 688-705, https://doi.org/10.17675/2305-6894-2020-9-2-19.

44. Zinad, D.S.; Hanoon, M.; Salim, R.D.; Ibrahim, S.I.; Al-Amiery, A.A.; Takriff, M.S.; Kadhum, A.A.H. A New Synthesized Coumarin-Derived Schiff Base as a Corrosion Inhibitor of Mild Steel Surface in Hcl Medium: Gravimetric and Dft Studies. Int. J. Corros. Scale Inhib. 2020, 9, 228-243, https://doi.org/10.17675/2305-6894-2020-9-1-14.

45. Zinad, D.S.; Jawad, Q.A.; Hussain, M.A.M.; Mahal, A.; Mohamed, L.; Al-Amiery, A.A. Adsorption, Temperature and Corrosion Inhibition Studies of a Coumarin Derivatives Corrosion Inhibitor for Mild Steel in Acidic Medium: Gravimetric and Theoretical Investigations. Int. J. Corros. Scale Inhib. 2020, 9, 134-151, https://doi.org/10.17675/2305-6894-2020-9-1-8. 
46. Alamiery, A.; Mahmoudi, E.; Allami, T. Corrosion Inhibition of Low-Carbon Steel in Hydrochloric Acid Environment Using a Schiff Base Derived from Pyrrole: Gravimetric and Computational Studies. Int. J. Corros. Scale Inhib. 2021, 10, 749-765, https://doi.org/10.17675/2305-6894-2021-10-2-17.

47. Resen, A.M.; Hanoon, M.; Salim, R.D.; Al-Amiery, A.A.; Shaker, L.M.; Kadhum, A.A.H. Gravimetrical, Theoretical, and Surface Morphological Investigations of Corrosion Inhibition Effect of 4-(Benzoimidazole2-Y1) Pyridine on Mild Steel in Hydrochloric Acid. Koroze a Ochr. Mater. 2020, 64, https://doi.org/10.2478/kom-2020-0018.

48. Salman, T.A.; Zinad, D.S.; Jaber, S.H.; Al-Ghezi, M.; Mahal, A.; Takriff, M.S.; Al-Amiery, A.A. Effect of 1,3,4-Thiadiazole Scaffold on the Corrosion Inhibition of Mild Steel in Acidic Medium: An Experimental and Computational Study. J. Bio- Tribo-Corrosion 2019, 5, 1-11, https://doi.org/10.1007/s40735-019-02437.

49. Al-Baghdadi, S.B.; Hashim, F.G.; Salam, A.Q.; Abed, T.K.; Gaaz, T.S.; Al-Amiery, A.A.; Kadhum, A.A.H.; Reda, K.S.; Ahmed, W.K. Synthesis and Corrosion Inhibition Application of NATN on Mild Steel Surface in Acidic Media Complemented with DFT Studies. Results Phys. 2018, 8, 1178-1184, https://doi.org/10.1016/j.rinp.2018.02.007.

50. Kadhim, A.; Al-Okbi, A.K.; Jamil, D.M.; Qussay, A.; Al-Amiery, A.A.; Gaaz, T.S.; Kadhum, A.A.H.; Mohamad, A.B.; Nassir, M.H. Experimental and Theoretical Studies of Benzoxazines Corrosion Inhibitors. Results Phys. 2017, 7, 4013-4019, https://doi.org/10.1016/j.rinp.2017.10.027.

51. Wang, H.; Wang, X.; Wang, H.; Wang, L.; Liu, A. DFT Study of New Bipyrazole Derivatives and Their Potential Activity as Corrosion Inhibitors. J Mol Model 2007, 13, 147-153, https://doi.org/10.1007/s00894006-0135-x.

52. Obayes, H.R.; Al-Amiery, A.A.; Alwan, G.H.; Abdullah, T.A.; Kadhum, A.A.H.; Mohamad, A.B. Sulphonamides as Corrosion Inhibitor: Experimental and DFT Studies. J. Mol. Struct. 2017, 1138, 1-9, https://doi.org/10.1016/j.molstruc.2017.02.100.

53. Junaedi, S.; Al-Amiery, A.A.; Kadihum, A.; Kadhum, A.A.H.; Mohamad, A.B. Inhibition Effects of a Synthesized Novel 4-Aminoantipyrine Derivative on the Corrosion of Mild Steel in Hydrochloric Acid Solution Together with Quantum Chemical Studies. Int. J. Mol. Sci. 2013, 14, 11915-11928, https://doi.org/10.3390/ijms140611915.

54. Fu, J.; Zang, H.; Wang, Y.; S. Li, T.; Chen, X. L. Experimental and Theoretical Study on the Inhibition Performances of Quinoxaline and Its Derivatives for the Corrosion of Mild Steel in Hydrochloric Acid. Ind. Eng. Chem. Res. 2012, 51, 6377-6386, https://doi.org/10.1021/ie202832e.

55. Guo, L.; Obot, I.; Zheng, B.; Shen, X.; Qiang, Y.; Kaya, S. Kaya, Theoretical Insight into an Empirical Rule about Organic Corrosion Inhibitors Containing Nitrogen, Oxygen, and Sulfur Atoms. Appl. Surf. Sci. 2017, 406, 301-306, https://doi.org/10.1016/j.apsusc.2017.02.134.

56. Masoud, M.; Awad, M.; Shaker, M.; El-Tahawy, M. The Role of Structural Chemistry in the Inhibitive Performance of Some Aminopyrimidines on the Corrosion of Steel. Corros. Sci. 2010, 52, 2387-2396, https://doi.org/10.1016/j.corsci.2010.04.011.

57. Mert, B.; Yüce, A.; Kardaş, G.; Yazıcı, B. Inhibition Effect of 2-Amino-4-Methylpyridine on Mild Steel Corrosion: Experimental and Theoretical Investigation. Corros. Sci. 2014, 85, 287-295, https://doi.org/10.1016/j.corsci.2014.04.032.

58. Al-Sabagh, A.; Basiony, N.E.; Sadeek, S.; Migahed, M. Scale and Corrosion Inhibition Performance of the Newly Synthesized Anionic Surfactant in Desalination Plants: Experimental, and Theoretical Investigations. Desalination 2018, 437, 45-58, https://doi.org/10.1016/j.desal.2018.01.036.

59. El-Belghiti, M.; Karzazi, Y.; Dafali, A.; Hammouti, B.; Bentiss, F.; Obot, I.; Bahadur, I.; Ebenso, E. Experimental, Quantum Chemical and Monte Carlo Simulation Studies of 3, 5-Disubstituted-4-Amino-1, 2, 4-Triazoles as Corrosion Inhibitors on Mild Steel in Acidic Medium. J. Mol. Liq. 2016, 218, 281-293, https://doi.org/10.1016/j.molliq.2016.01.076.

60. Ebenso, E.; Arslan, T.; Kandemirli, F.; Caner, N.; Love, I. Quantum Chemical Studies of Some Rhodanine Azosulpha Drugs as Corrosion Inhibitors for Mild Steel in Acidic Medium. Int. J. Quantum Chem. 2010, 110, 1003-1018, https://doi.org/10.1002/qua.22249. 